\title{
Pilonidal Sinus Management; Bascom Flap Versus Pilonidal Pits Excision: A Single-Center Experience
}

\author{
Ashraf Imam*, Harbi Khalayleh*, Guy Pines, Deeb Khoury, Eli Mavor, Arie Pelta \\ Department of General Surgery, Kaplan Medical Center, Rehovot; Hebrew University School of Medicine, Jerusalem, Israel
}

Purpose: This study aimed to evaluate the outcomes of the Bascom cleft lift (flap) and the pilonidal pits excision (Gips procedure).

Methods: The records of all the patients who underwent pilonidal sinus excision between November 2013 and August 2017 were reviewed. Inclusion criteria included either pilonidal pits excision or the Bascom cleft lift procedure. All procedures were performed by a single surgeon. Perioperative complications and recurrence rates were reviewed.

Results: Fifty-three patients met the inclusion criteria. Male/female ratio was 36/17, with a mean age of $23.4 \pm 7$ years. In this study, 21 patients underwent the Bascom cleft lift (skin flap) procedure and 32 underwent the Gips-style operation. The mean follow-up was 3.5 months. Twenty-eight patients (52.8\%) underwent prior drainage of pilonidal abscess. Eleven patients had a previous wide local excision with recurrent disease. A higher rate of recurrence was observed among patients who underwent pits picking following failure of a previous wide local excision ( $80 \%$ vs. $0 \%, P=0.02)$. Minor wound dehiscence developed in 8 patients; all of which were in the Bascom flap group ( $40 \%$ vs. $0 \%, P<0.005)$. All of these wounds healed completely between 3 and 6 weeks.

Conclusion: The Gips procedure is the recommended treatment for simple pilonidal disease. For recurrent pilonidal disease, the Bascom cleft lift (flap) procedure is an excellent option since it demonstrates a short wound healing time and a good success rate. This calls into question the continued use of the wide excision technique used by most surgeons in this country and abroad.

Keywords: Pilonidal sinus; Minimally invasive surgical procedures; Abscess; Drainage; Surgical flaps

\section{INTRODUCTION}

The surgical management of pilonidal disease is in a state of flux with a shift away from the larger morbid operations which involve

Received: Mar 29, 2019 • Revised: May 24, 2019 • Accepted: Nov 19, 2019 Correspondence to: Harbi Khalayleh, M.D.

Department of General Surgery, Kaplan Medical Center, Derekh Pasternak, Bilu Junction, Rehovot 76100, Israel

Tel: +972-8944-1295, Fax: +972-8944-1888

E-mail: kraceve30@hotmail.com

ORCID: https://orcid.org/0000-0002-6706-3837

*Ashraf Imam and Harbi Khalayleh contributed equally to this study as cofirst authors.

- This study was presented at the biannual meeting of the Israeli Surgical Association, May 2017.

(C) 2021 The Korean Society of Coloproctology

This is an open-access article distributed under the terms of the Creative Commons Attribution NonCommercial License (https://creativecommons.org/licenses/by-nc/4.0) which permits unrestricted noncommercial use, distribution, and reproduction in any medium, provided the original work is properly cited. wide excision of the sinus containing tissue, down to the post sacral fascia combined with either primary or flap closure [1]. These larger procedures have favored the use of off-midline closures which shift the suture line away from the natal cleft, showing a lower recurrence rate when compared with midline closure techniques [2, 3]. Off-midline flap procedures (Karydakis, Bascom cleft lift, Limberg, and V-Y plasty) have been reported with variable success rates [4-7] with published comparisons between these types of operations [8-10] and with simple closure [11-13].

Formal excision and closure procedures result in a varying necessity for patient hospitalization along with the need for general or regional anesthesia and variable use of drains and antibiotics. The reported recurrence rates are based upon studies with heterogeneous periods of follow-up.

However, in meta-analyses, recurrences have generally been less with open secondary healing methods $[14,15]$. Simple pit-picking and debridement were described in 1965 by Lord and Millar [16] as well as by Bascom [17] with a modification of this procedure 
revived by Gips et al. [18] who showed rapid healing and low recurrence rates over a medium- to long-term follow-up. These initial results of a procedure performed as a day case (ambulatory surgery) under local anesthesia have been confirmed by other authors using similar techniques of localized sinusectomy [19], or limited removal of pilonidal pits and the underlying soft tissue fistulous tracks with skin trephines $[20,21]$.

Herein, we present a single-center experience of a range of techniques (principally using the Bascom cleft lift procedure or the Gips-style operation) with medium-term outcomes for elective pilonidal sinus treatment.

\section{METHODS}

Institutional Review Board of Kaplan Medical Center approved this study (0053-18-KMC) and waived the need for written consent. The records of all patients who underwent pilonidal disease surgery between November 2013 and August 2017 were reviewed. All procedures were performed by a single surgeon at a university hospital. The medical records were scrutinized for elective pilonidal sinus excision using the International Classification of Diseases (ICD) 10 Codes (L.05.9). Acute cases of abscess drainage (L05.0) [22] and simple wide local excision were excluded.

The treatment of simple pilonidal disease presenting with small pilonidal pits was achieved using the pits picking procedure (Gips). For a clinically complex pilonidal disease, the Bascom cleft lift procedure (flap) was preferred.

Perioperative antibiotics prophylaxis (first-generation cephalosporins) were administered 1 hour before incision only for flap procedures. Patients undergoing a Bascom flap procedure were discharged on amoxicillin/clavulanate $875 \mathrm{mg}$ twice a day for 1 week postoperatively. All flap procedures were performed under general anesthesia with local anesthesia infiltration ( $0.5 \%$ bupivacaine $+1: 200,000$ adrenaline) with patients positioned in the prone position. In all cases, the gluteal area was shaved, and an ellipse of skin was marked to include the pilonidal complex.

Demographic data of the patients were collated along with the incidence of complications and assessment of healing at the 1st, $3 \mathrm{rd}$, and 6th postoperative weeks. Wound infection was defined as erythema and swelling with or without purulent wound discharge. Recurrence was recorded for 2 indications; if the surgical wound had initially completely healed and there was a need for further operative intervention for repeat excision. Or, if there was formation of a new sinus and the presence of hair in a new skin opening, in accordance with descriptions by Doll et al. [23].

\section{Surgical techniques}

Two types of operations were performed. The choice of procedure was at the surgeon's discretion. The Bascom cleft lift operation [6, $17,24]$ creates a shift of the natal cleft by an eccentric elliptical excision, using a part of a skin ellipse which was marked preoperatively. This accomplishes mobilization of a full-thickness flap, removal of deep abscess granulations, and creation of a shallow cleft floor (Fig. 1). This procedure was favored over the Karydakis operation $[5,25]$ which only shifts skin alone and does not specifically reduce the depth of the natal cleft. When the Karydakis flap was used, the excision was continued down to the postsacral fascia with a straight edge on the side of the flap mobilization along with medial mobilization of the flap across the midline. Closed suction drains (Jackson Pratt \#7) were routinely placed for patients undergoing a Bascom flap, and were removed after the drainage decreased below $25 \mathrm{~mL} /$ day. All incisions were closed with absorbable subcutaneous Vicryl (Ethicon Corp., Cornelia, GA, USA) and subcuticular Monocryl sutures (Ethicon Corp.). A pressure dressing was routinely placed over wounds (Fig. 1). Dressings were removed on the first postoperative day.

The pits picking (Gips) procedures $[18,20]$ were all carried out in the prone position under a general and local anesthesia combi-


Fig. 1. Bascom cleft-lift procedure. (A) Eccentric skin ellipse excision. (B) Superficial flaps are established to reduce the depth of the gluteal cleft and to shift the suture line off the midline. (C) The wound after 6 weeks. 
nation as described before. Initial probing delineated of the depth and direction of the tracks, followed by coring out these areas using a Seamless Premier Uni-Punch Disposable Biopsy trephine (Premier Medical, Plymouth, PA, USA) of 3 sizes (4-, 6-, and 8-mm diameter) depending upon the pit size. Adjacent pits were excised simultaneously with the larger trephine. Attempts were made to remove all epithelialized openings and scarred fistulae (Fig. 2). The goal was to thoroughly clean all of the cavities and associated tracks of hair, debris, and granulation tissue. A gauze pad on a mosquito clamp was passed through all wounds for vigorous debridement. Patients were observed in the post-anesthesia care unit for bleeding prior to discharge. Follow-up visits were performed in the outpatient surgery clinic. When complete healing was observed after 6 weeks (on average), the patients were subsequently referred for local laser hair removal treatment.

\section{Statistical analysis}

The Student t-test, as well as the nonparametric Mann-Whitney test, was used in order to compare quantitative variables between 2 independent groups. For more than 2 groups, the ANOVA procedure was used. In order to assess the association between categorical variables, the chi-square and the Fisher exact tests were used. All tests applied were 2 -tailed, and a P-value of $5 \%$ or less was considered statistically significant.

\section{RESULTS}

One hundred 35 patients underwent pilonidal sinus surgery during the study period, of which, 53 met the inclusion criteria (Table 1 ). The male/female ratio was $36 / 17$, with a mean age of $23.4 \pm 7$
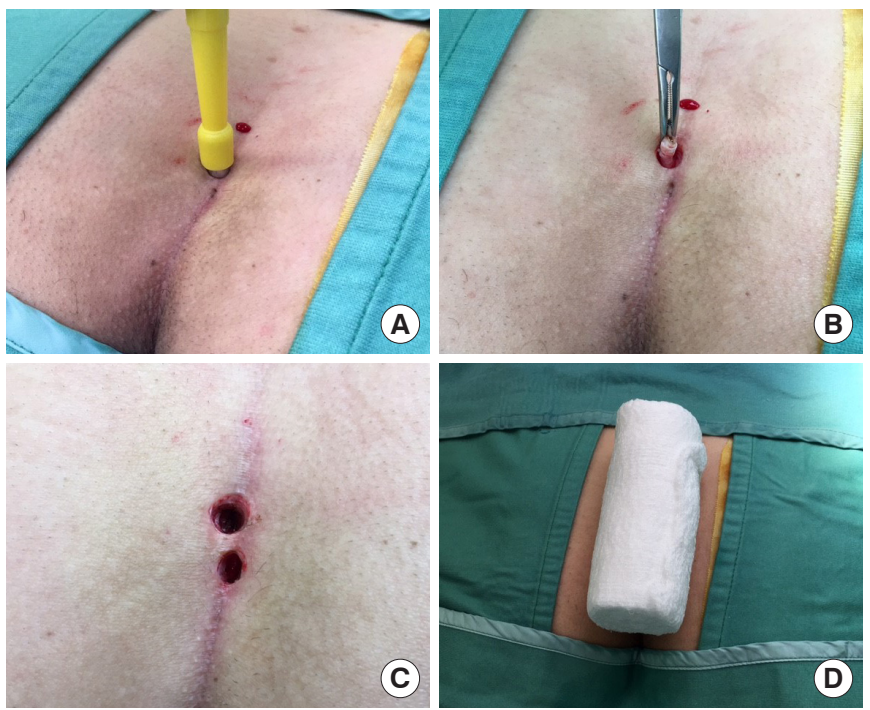

Fig. 2. Gips-style trephine procedure. (A, B) Minimalist excision of the scarred track. (C) Appearance of the pits after excision. (D) Standard gauze roll pressure dressing used for all operations. years. Of these, 21 patients underwent a flap procedure (20 Bascom flap and 1 Karydakis flap; male/female, 14/7; mean age, $23.7 \pm 3.4$ years). Whereas, 32 patients underwent the Gips-style procedures (male/female, 22/10; mean age, $23.5 \pm 7.2$ years).

All procedures were performed in an ambulatory surgery center. The mean follow-up was 3.5 months (range, 1 to 12 months). Twenty-eight patients (52.8\%) underwent prior drainage of pilonidal abscess. Eleven patients (20.7\%) had a history of a previous wide local excision operation with recurrent disease. From this cohort, the pits excision was performed in 5 patients and the Bascom flap was performed in 6 patients. All cases of recurrent disease occurred in the pits-excision (Gips) group (4 patients). Minor wound dehiscence developed in 8 patients from the Bascom flap cohort $(38 \%$ vs. $0 \%, \mathrm{P}<0.005)$. All wounds subsequently healed completely between 3 and 6 weeks. Surgical failure with

Table 1. Demographic and clinical characteristic of patients

\begin{tabular}{lcccc}
\hline Variable & All cases & Bascom flap & Pits excision & P-value $^{\mathrm{a}}$ \\
\hline Patient & $53(100)$ & $21(39.6)$ & $32(60.4)$ & \\
Age (yr) & $23.4 \pm 7.0$ & $23.7 \pm 3.4$ & $23.5 \pm 7.2$ & 0.875 \\
Sex & & & & 0.875 \\
$\quad$ Male & $36(67.9)$ & $14(66.7)$ & $22(68.8)$ & \\
$\quad$ Female & $17(32.1)$ & $7(33.3)$ & $10(31.3)$ & \\
Previous drainage & & & & 0.085 \\
$\quad$ Yes & $28(52.8)$ & $8(38.1)$ & $20(62.5)$ & \\
$\quad$ No & $25(47.2)$ & $13(61.9)$ & $12(37.5)$ & \\
Previous WLE & $11(20.8)$ & $6(28.6)$ & $5(15.6)$ & 0.351 \\
Follow-up (mo) & $3.5 \pm 2.89(1-12)$ & $3.4 \pm 2.7(1-12)$ & $3.6 \pm 3.1(1-12)$ & 0.978 \\
\hline
\end{tabular}

Values are presented as number (\%) or mean \pm standard deviation (range).

WLE, wide local excision.

aMann-Whitney test.

Table 2. Surgical outcome, postoperative complication and recurrence rate

\begin{tabular}{lccr}
\hline Variable & $\begin{array}{c}\text { Bascom flap } \\
(\mathrm{n}=21)\end{array}$ & $\begin{array}{c}\text { Pits excision } \\
(\mathrm{n}=32)\end{array}$ & P-value $^{\mathrm{a}}$ \\
\hline Healing time (wk) & $5.7 \pm 3.4$ & $5.4 \pm 3.0$ & 0.812 \\
Operation time (min) & $25.4 \pm 16.0$ & $26.4 \pm 16.3$ & 0.287 \\
Wound infection & $2(9.5)$ & $3(9.4)$ & 0.986 \\
Dehiscence & $8(38.1)$ & $0(0)$ & $<0.005$ \\
Failure & $0(0)$ & $8(25.0)$ & 0.014 \\
Reoperation & $0(0)$ & $3(9.4)$ & 0.152 \\
Recurrence overall & $6(28.6)$ & $5(15.6)$ & 0.260 \\
Recurrence of cases that have previous & $0 / 6(0)$ & $4 / 5(80.0)$ & 0.020 \\
WLE $(\mathrm{n}=11)$ & & & \\
\hline
\end{tabular}

Values are presented as number (\%) or mean \pm standard deviation (range).

WLE, wide local excision.

aMann-Whitney test. 
recurrent disease, only occurred in the pits-excision group (8 patients, $25 \%$ vs. $0 \% ; \mathrm{P}=0.014$ ). Of these failed cases, 6 patients had previously undergone incision and drainage of a pilonidal abscess. In addition, 4 of these patients had previously undergone wide local excision, as mentioned earlier (Table 2).

Three of the patients who developed recurrent disease underwent redo surgery. One patient underwent a pits excision (Gips). The second patient underwent a wide local excision at another hospital; whereas, the third patient required incision and drainage of a pilonidal abscess.

\section{DISCUSSION}

This small single surgeon experience of pilonidal disease surgery demonstrates an excellent medium-term outcome for both the selective use of the Bascom cleft lift procedure (flap) as well as for the minimal Gips-style pit-excision operation. The aims of surgery in these predominantly young patients are to minimize the community cost imposed by work absences, to reduce the need for dressing changes and postoperative visits, and to reduce the overall complications of management including the incidence of recurrence. The ideal operation for pilonidal disease should be relatively simple with the shortest hospital stay possible, affording rapid healing, minimal postoperative pain, a low recurrence rate, and an acceptable cosmetic appearance.

The typical procedures used for pilonidal sinus management (open wounds, suture closed wounds, and flaps) are not strictly comparable as the management philosophy will directly affect the length of hospital stay, the need for postoperative visits, the requirement for painful dressing changes, and the overall recorded healing time. For some of these procedures, the advantage of same-day surgery may be obviated by a longer convalescence and the requirement for secondary surgery. Our results of the Bascom cleft lift flap with an off-midline closure compare favorably with large reported studies $[2,3,14]$. With the Bascom operation, it is recommended that extension of the lower end of the excision should be conducted laterally away from the postanal area so as to avoid the need to close deeper postanal wounds which are typically accompanied by delayed healing and more wound-related morbidity. This type of approach is more in keeping with Bascom's assertion that there is merit in reshaping the gluteal cleft.

Whereas, with the simpler sinusectomy (Gips pits excision) operation, the deeper tissues are left in place without a need to fashion thick flaps [24]. The Gips technique is comparatively easier to perform and to teach compared to the more complex flap operations and is associated with a relatively brief healing time and a low recurrence rate $[9,10,25,26]$. When the Bascom cleft lift operation is performed, an attempt is made to reduce the amount of excision of surrounding healthy fatty tissue and to confine the excision to sinus tissue only. Such an approach which minimalizes the soft-tissue excision during flap construction is associated with less wound dehiscence and infection in nonrandomized studies
$[26,27]$ and with less morbidity than a typical Karydakis procedure [28]. We routinely used wound drainage for the Bascom flap, with Jackson Pratt \#7 drains, although it has been recently shown that drain usage may be obviated by a compressive short-term tieover dressing [29]. Future management should assess the potential benefit of selective drain use which will likely affect the risk of delayed infection and overall costs.

In accordance with the theory of pilonidal sinus disease as an epidermal rather than a deep tissue problem, our initial results with the Gips-style pit excision have been favorable and this operative success is in keeping with other reports [18, 20, 21]. Recurrence may effectively be treated with a repeat Gips procedure although this has been variably used in between one-third of cases in a large series by Di Castro et al. [20] (2,347 cases with 137 recurrences) and in $76.9 \%$ of the recurrent cases as reported by Gips et al. [18] (1,358 cases with 54 reoperated patients). In both series, as in our cases, surgical flap alternatives are reserved for more extensive or bilateral recurrences. The punch trephines operate as facile debridement instruments which provide functional drainage ports and which leave adjacent healthy tissue in place permitting a supportive peri-fistula structure and allowing more symmetric and cosmetic healing without lateral traction.

Our study has several important limitations. There are only a small number of patients who have been retrospectively assessed with only a medium-term follow-up. In this respect, the majority of recurrences in pilonidal sinus will occur within the first 2 years after surgery [23]; however, late recurrence is well recorded. As the surgeon (AP) is one of several surgeons performing flap surgery for pilonidal sinus in Israel, it is expected that patients with recurrence will return to our clinic. Initially, our surgical unit performed the minimal Bascom procedure; however, we switched to the Gips operation which appeared simpler and more efficient with reduced operative time. The problem of inferior wound separation of the perianal part of the Bascom flap was eliminated by the placement of interrupted skin sutures in this area. Despite the limitations of clinical comparison, our cases were not randomized to different surgical procedures. It is accepted that a comparative prospective randomized controlled trial is required in order to see the beneficial effects of the more minimalist style surgery and the potential ancillary cost benefits. In this regard, there are currently very few randomized studies assessing the different surgical treatments for chronic pilonidal disease [3] and future designs will need to also incorporate a video-assisted arm of treatment. In summary, the minimalist Gips-style operation is effective for elective pilonidal sinus with a Bascom cleft lift procedure associated with excellent results when reserved for more extensive disease. Our experience presented here represents the only Israeli surgical unit performing selective flap surgery for recurrent or complicated pilonidal disease. In general, wide local excision of relatively healthy tissue is unnecessary and it is salutary to heed the words of Patey [30] who wrote back in 1970 that it was "not essential for cure". His further adage "Don't take a hammer to swat a fly" re- 
mains, however, in the face of newer more minimalist and endoscopic approaches, as true today as when it was first articulated.

Both Bascom cleft lift and pits picking are safe and effective treatment for pilonidal disease. Even though the Bascom flap carries a slightly higher morbidity rate, it should be considered among patients who previously failed wide local excision of pilonidal disease.

\section{CONFLICT OF INTEREST}

No potential conflict of interest relevant to this article was reported.

\section{REFERENCES}

1. Enriquez-Navascues JM, Emparanza JI, Alkorta M, Placer C. Meta-analysis of randomized controlled trials comparing different techniques with primary closure for chronic pilonidal sinus. Tech Coloproctol 2014;18:863-72.

2. Petersen S, Koch R, Stelzner S, Wendlandt TP, Ludwig K. Primary closure techniques in chronic pilonidal sinus: a survey of the results of different surgical approaches. Dis Colon Rectum 2002;45: 1458-67.

3. Sevinç B, Karahan Ö, Okuş A, Ay S, Aksoy N, Şimşek G. Randomized prospective comparison of midline and off-midline closure techniques in pilonidal sinus surgery. Surgery 2016;159:74954.

4. Arslan K, Said Kokcam S, Koksal H, Turan E, Atay A, Dogru O. Which flap method should be preferred for the treatment of pilonidal sinus? A prospective randomized study. Tech Coloproctol 2014;18:29-37.

5. Karydakis GE. New approach to the problem of pilonidal sinus. Lancet 1973;2:1414-5.

6. Bascom JU. Pilonidal sinus. Curr Pract Surg1994;6:175-80.

7. Dýlek ON, Bekereciodlu M. Role of simple V-Y advancement flap in the treatment of complicated pilonidal sinus. Eur J Surg 1998; 164:961-4.

8. Mentes O, Bagci M, Bilgin T, Ozgul O, Ozdemir M. Limberg flap procedure for pilonidal sinus disease: results of 353 patients. Langenbecks Arch Surg 2008;393:185-9.

9. Can MF, Sevinc MM, Hancerliogullari O, Yilmaz M, Yagci G. Multicenter prospective randomized trial comparing modified Limberg flap transposition and Karydakis flap reconstruction in patients with sacrococcygeal pilonidal disease. Am J Surg 2010; 200:318-27.

10. Guner A, Boz A, Ozkan OF, Ileli O, Kece C, Reis E. Limberg flap versus Bascom cleft lift techniques for sacrococcygeal pilonidal sinus: prospective, randomized trial. World J Surg 2013;37:207480.

11. Mahdy T. Surgical treatment of the pilonidal disease: primary closure or flap reconstruction after excision. Dis Colon Rectum 2008; 51:1816-22.
12. Nursal TZ, Ezer A, Calişkan K, Törer N, Belli S, Moray G. Prospective randomized controlled trial comparing V-Y advancement flap with primary suture methods in pilonidal disease. Am J Surg 2010;199:170-7.

13. Muzi MG, Milito G, Cadeddu F, Nigro C, Andreoli F, Amabile D, et al. Randomized comparison of Limberg flap versus modified primary closure for the treatment of pilonidal disease. Am J Surg 2010;200:9-14.

14. McCallum IJ, King PM, Bruce J. Healing by primary closure versus open healing after surgery for pilonidal sinus: systematic review and meta-analysis. BMJ 2008;336:868-71.

15. Al-Khamis A, McCallum I, King PM, Bruce J. Healing by primary versus secondary intention after surgical treatment for pilonidal sinus. Cochrane Database Syst Rev 2010;2010:CD006213.

16. Lord PH, Millar DM. Pilonidal sinus: a simple treatment. Br J Surg 1965;52:298-300.

17. Bascom J. Pilonidal disease: origin from follicles of hairs and results of follicle removal as treatment. Surgery 1980;87:567-72.

18. Gips M, Melki Y, Salem L, Weil R, Sulkes J. Minimal surgery for pilonidal disease using trephines: description of a new technique and long-term outcomes in 1,358 patients. Dis Colon Rectum 2008; 51:1656-62.

19. Soll C, Dindo D, Steinemann D, Hauffe T, Clavien PA, Hahnloser D. Sinusectomy for primary pilonidal sinus: less is more. Surgery 2011;150:996-1001.

20. Di Castro A, Guerra F, Levi Sandri GB, Ettorre GM. Minimally invasive surgery for the treatment of pilonidal disease: the Gips procedure on 2347 patients. Int J Surg 2016;36:201-5.

21. Levinson T, Sela T, Chencinski S, Derazne E, Tzur D, Elad H, et al. Pilonidal sinus disease: a 10-year review reveals occupational risk factors and the superiority of the minimal surgery trephine technique. Mil Med 2016;181:389-94.

22. Steele SR, Perry WB, Mills S, Buie WD; Standards Practice Task Force of the American Society of Colon and Rectal Surgeons. Practice parameters for the management of pilonidal disease. Dis Colon Rectum 2013;56:1021-7.

23. Doll D, Krueger CM, Schrank S, Dettmann H, Petersen S, Duesel W. Timeline of recurrence after primary and secondary pilonidal sinus surgery. Dis Colon Rectum 2007;50:1928-34.

24. Bascom J, Bascom T. Failed pilonidal surgery: new paradigm and new operation leading to cures. Arch Surg 2002;137:1146-50.

25. Kitchen PR. Pilonidal sinus: experience with the Karydakis flap. Br J Surg 1996;83:1452-5.

26. Guner A, Ozkan OF, Kece C, Kesici S, Kucuktulu U. Modification of the Bascom cleft lift procedure for chronic pilonidal sinus: results in 141 patients. Colorectal Dis 2013;15:e402-6.

27. Abdelrazeq AS, Rahman M, Botterill ID, Alexander DJ. Shortterm and long-term outcomes of the cleft lift procedure in the management of nonacute pilonidal disorders. Dis Colon Rectum 2008;51:1100-6.

28. Keshava A, Young CJ, Rickard MJ, Sinclair G. Karydakis flap repair for sacrococcygeal pilonidal sinus disease: how important is 


\section{Coloproctology Ashraf Imam, et al.}

technique? ANZ J Surg 2007;77:181-3.

29. Sewefy AM, Hassanen A, Atyia AM, Saleh SK. Karydakis flap with compressing tie-over interrupted sutures without drain versus standard Karydakis for treatment of sacrococcygeal pilonidal sinus disease. Dis Colon Rectum 2017;60:514-20.

30. Patey DH. The principles of treatment of sacrococcygeal pilonidal sinus. Proc R Soc Med 1970;63:939-40. 